\title{
Mechanochemical Reaction of Polymers by Ultrasonic Irradiation. V. Mechanochemical Copolymerization in Mixtures of Poly(vinyl chloride), Styrene, and Solvents
}

\author{
Hideki FujIWARA, Kooji KIMURA, Hideki MORI, \\ and Kunio GoTo \\ Department of Applied Chemistry, Osaka Institute of Technology, \\ 16-1, Omiya 5-chome, Asahi-ku, Osaka 535, Japan.
}

(Received November 29, 1980)

\begin{abstract}
Mechanical degradation and mechanochemical block copolymerization in poly(vinyl chloride)-styrene-solvent mixtures were studied using ultrasonic irradiation at $60^{\circ} \mathrm{C}$. The effects of the concentrations of poly(vinyl chloride), styrene, and solvents on mechanical degradation were investigated. The rate equation for mechanical scission agreed with an expression given earlier. The rate constant for mechanical degradation was obtained from the change in the number of scissions of poly(vinyl chloride). In addition, the effects of the concentrations of poly(vinyl chloride) and styrene on mechanochemical block copolymerization were investigated. The rate equation for mechanochemical copolymerization was deduced, and the experimental results were in fair agreement with this equation. Changes in the amounts of the block copolymer, poly(vinyl chloride), and polystyrene in the reaction products were followed by turbidimetric titration. The apparent block ratio, the ratio of the poly(vinyl chloride) units in the block copolymer to the total poly(vinyl chloride) content, was $c a .80 .1 \%$.

KEY WORDS Mechanical Degradation / Mechanochemical Copolymerization / Ultrasonic Irradiation / Poly(vinyl chloride) / Styrene / Rate Equation / Block Copolymer / Apparent Block Ratio /
\end{abstract}

In the 1930's, ultrasonic irradiation was introduced as a means of producing the mechanical degradation of polymer chains in solution. ${ }^{1}$ Since then, many studies have been made to elucidate the process involved. ${ }^{2-16}$

On the other hand, the polymerizations of vinyl monomers by the polymeric free radicals produced by ultrasonic irradiation have not been fully studied, and there have been only a few published reports on mechanochemical polymerization. ${ }^{17-23}$

In earlier papers, a study was made of mechanochemical polymerizations in polystyrene-styrenecyclohexanone mixtures, ${ }^{19}$ polystyrene-methyl methacrylate mixtures, ${ }^{21}$ polybutadiene-styrene mixtures, ${ }^{23}$ and polybutadiene-methyl methacrylate mixtures ${ }^{23}$ by ultrasonic irradiation.

In the present paper, we report work on mechanical degradation and mechanochemical copolymerization in systems of poly(vinyl chloride)-styrene- solvent effected by irradiation. In particular, we deal with the kinetics of the copolymerization and the composition of the block copolymer and homopolymer formed in the reaction products.

\section{EXPERIMENTAL}

\section{Materials}

Poly(vinyl chloride) (2B-719, Teijin Ltd.) was purified by extraction with hot pure methanol for $80 \mathrm{~h}$. The initial number-average chain length was 1,530 monomer residues.

The styrene monomer was washed successively with sodium thiosulfate solution, water, sodium hydroxide solution, and water. After drying over barium oxide, the monomer was filtered and purified by vacuum distillation under nitrogen.

Purified tetrahydrofuran and cyclohexanone were used as polymerization solvents and purified meth- 
anol was used as the precipitating agent.

\section{Apparatus and Procedures}

An ultrasonic generator (Model USV-150V, ChoOnpa Kogyo Ltd.) equipped with an electrostrictive barium titanate vibrator of diameter $6.0 \mathrm{~cm}$ and thickness $1.2 \mathrm{~cm}$ was used. ${ }^{21,23}$ The vibrator output was 7.4 watts $/ \mathrm{cm}^{2}$ at a constant frequency of 200 $\mathrm{kHz}$.

The reaction temperature was controlled by an electronic bath circulator (Model TE-104, Sharp Ltd.).

In the procedure for mechanical degradation, poly(vinyl chloride) was dissolved in a solvent (tetrahydrofuran and tetrahydrofuran-cyclohexanone mixtures) containing a $p$-benzoquinone inhibitor at $40^{\circ} \mathrm{C}$, and then the styrene monomer was added slowly to the solution with stirring at a temperature of $-10^{\circ} \mathrm{C}$. Ten mililiters of solution was poured into a $25 \mathrm{ml}$ glass ampoule, which was then degassed and sealed under one atmospheric pressure of dry nitrogen. Ultrasonic irradiation of the polymer solution was carried out for $10,20,30$, 40,50 , and 70 minutes at $60 \pm 0.1^{\circ} \mathrm{C}$. The distance between the surface of the vibrator and the center of the bottom of the sealed ampoule was $9.2 \mathrm{~mm}$. After treatment, the solution was poured into a large amount of methanol containing $p$-benzoquinone inhibitor. The precipitated polymer was filtered, washed, and dried in vacuo at $40^{\circ} \mathrm{C}$, and then the weight of the polymer was measured. The numberaverage chain length at various stages of mechanical degradation was determined by osmometry.

Mechanochemical copolymerization was carried out by the irradiation of poly(vinyl chloride)styrene-solvent mixtures in the absence of $p$ benzoquinone. The amount of styrene conversion was calculated from the weight of fresh polymer produced by the polymerization. The composition of the copolymer and homopolymer in the reaction products was determined by turbidimetry.

\section{Measurement of Osmotic Pressures}

Osmotic pressures of tetrahydrofuran solutions were measured with an electronic membrane osmometer (K. G. Dr.-Ing. Herbert Knauer GmbH) at $30 \pm 0.01^{\circ} \mathrm{C}$.

\section{Determination of Turbidities}

Solution turbidities were determined with a turbi- dimetric titrator (Model NT-3, Kotaki Works Ltd.) at $30^{\circ} \mathrm{C}$. The solvent and precipitating agent were tetrahydrofuran and distilled water, respectively. The polymer concentration was $0.10 \mathrm{gl}^{-1}$.

\section{RESULTS AND DISCUSSION}

\section{Mechanical Degradation}

The copolymerization of styrene by polymeric free radicals produced by ultrasonic irradiation was found to be completely inhibited in the presence of $p$-benzoquinone.

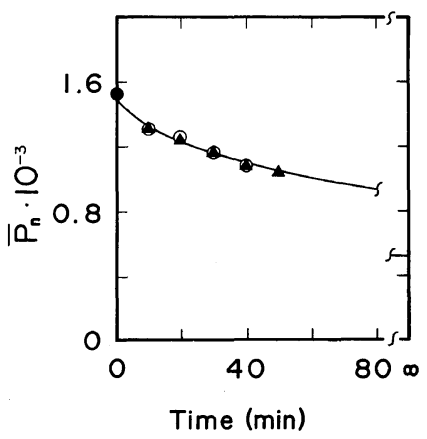

Figure 1. Effect of poly(vinyl chloride) concentrations on ultrasonic degradation: points determined by experiment, curve by calculation. [Poly(vinyl chloride)]: (O), $0.107 \mathrm{moll}^{-1}$; (A), $0.0534 \mathrm{moll}^{-1}$. [Styrene]: 2.31 moll ${ }^{-1}$. [Tetrahydrofuran]: $8.24 \mathrm{moll}^{-1}$. [Cyclohexanone]: $0 \mathrm{moll}^{-1}$. [ $p$-Benzoquinone]: $0.249 \mathrm{moll}^{-1}$.

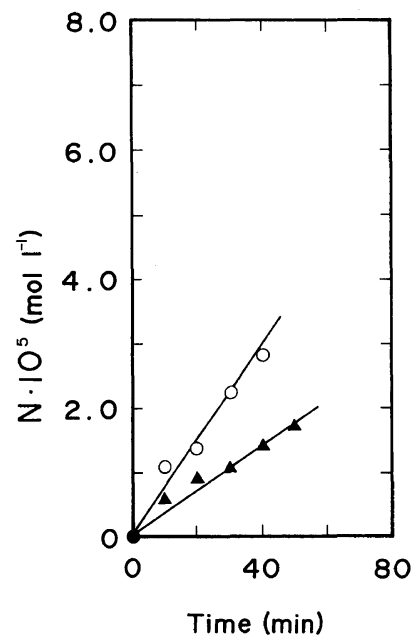

Figure 2. Number of poly(vinyl chloride) scissions $v s$. irradiation time. [Poly(vinyl chloride)]: (O), 0.107 moll ${ }^{-1}$; (A), $0.0534 \mathrm{moll}^{-1}$. [Styrene]: $2.31 \mathrm{moll}^{-1}$. [Tetrahydrofuran]: $8.24 \mathrm{moll}^{-1}$. [Cyclohexanone]: 0 moll ${ }^{-1}$. [ $p$-Benzoquinone]: $0.249 \mathrm{moll}^{-1}$. 
Changes in the number-average degree of polymerization $\bar{P}_{n}$ of ultrasonically degraded poly(vinyl chloride) in styrene-tetrahydrofuran- $p$-benzoquinone solutions are shown in Figure 1. The value of $\bar{P}_{n}$ decreases slowly with irradiation time, and the curve follows the rate equation for mechanical scission given in earlier papers ${ }^{19,24}$ to induce a final value, $\bar{P}_{n, \infty}=525$, calculated from the rate equation. In addition, the relation between $\bar{P}_{n}$ and irradiation time agrees well within the 0.0534 to $0.107 \mathrm{moll}^{-1}$ range.

Figure 2 shows the number of scissions $\left(\mathrm{moll}^{-1}\right)$ of poly(vinyl chloride) calculated from the results in Figure 1 with respect to irradiation time. The number of chain scissions increases linearly with increasing time. The gap between chain scissions rates is naturally attributed to the difference in their polymer concentrations. The rate constant $k_{\mathrm{d}}$ for mechanical degradation can be calculated from the following equation ${ }^{19,21,23}$ using the slopes of the straight lines from Figure 2.

$$
R_{\mathrm{d}}=\frac{2 \mathrm{~d} N}{\mathrm{~d} t}=2 k_{\mathrm{d}}\left[\mathrm{P}_{0}\right]
$$

where $R_{\mathrm{d}}, N$, and $\left[P_{0}\right]$ are, respectively, the initial rate of mechanical degradation, the number of moles of fresh polymer produced by the degradation, and the initial concentration of poly(vinyl chloride). Here, the rate constant $k_{\mathrm{d}}$ for mechanical degradation is $1.1 \times 10^{-7} \mathrm{~s}^{-1}$ (Table I).

The effect of the concentrations of styrene on ultrasonic degradation are shown in Figure 3. This experiment was carried out using the system of poly(vinyl chloride)-styrene-tetrahydrofuran- cyclohexane- $p$-benzoquinone. The rate of decrease in the number-average chain length of the degraded

Table I. Mechanical degradation rate constant $k_{\mathrm{d}}{ }^{\mathrm{a}}$

\begin{tabular}{ccc}
\hline $\begin{array}{c}\text { Poly(vinyl chloride) } \\
\text { concentration, } \\
{\left[\mathrm{P}_{0}\right]}\end{array}$ & $\begin{array}{c}\text { Initial rate of } \\
\text { degradation, } \\
R_{\mathrm{d}} \times 10^{8}\end{array}$ & $\begin{array}{c}\text { Rate constant, } \\
k_{\mathrm{d}} \times 10^{7}\end{array}$ \\
\hline $\mathrm{mol} \mathrm{1}^{-1}$ & $\mathrm{~mol} \mathrm{1}^{-1} \mathrm{~s}^{-1}$ & $\mathrm{~s}^{-1}$ \\
\hline 0.107 & 2.25 & 1.1 \\
0.0534 & 1.06 & 1.0 \\
\hline
\end{tabular}

a [Styrene], $2.31 \mathrm{~mol} \mathrm{1}^{-1}$; [Tetrahydrofuran], $8.24 \mathrm{~mol}$ $1^{-1}$; [Cyclohexanone], $0 \mathrm{~mol} \mathrm{1}^{-1}$; [p-Benzoquinone], $0.249 \mathrm{~mol} \mathrm{1}^{-1}$

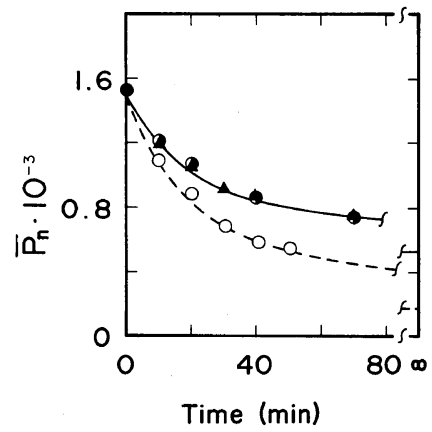

Figure 3. Effect of styrene concentrations on ultrasonic degradation: points determined by experiment, curves by calculation. [Styrene]: (O), $2.24 \mathrm{moll}^{-1}$; ( ) , $1.88 \mathrm{moll}^{-1} ;(\boldsymbol{\Delta}), 0.835 \mathrm{moll}^{-1}$. [Poly(vinyl chloride)]: $0.0660 \mathrm{moll}^{-1}$. [Cyclohexanone]/[Tetrahydrofuran] $=0.735$. [ $p$-Benzoquinone]: $0.241 \mathrm{moll}^{-1}$.

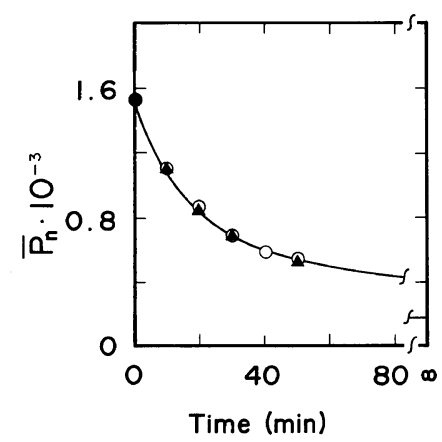

Figure 4. Effect of solvent concentrations on ultrasonic degradation: points determined by experiment, curve by calculation. [Cyclohexanone]/[Tetrahydrofuran]: ( $\mathbf{\Delta}), 2.97 ;(\bigcirc), 0.368$. [Poly(vinyl chloride)]: $0.0620 \mathrm{moll}^{-1}$. [Styrene]: $2.24 \mathrm{moll}^{-1}$. [ $p$-Benzoquinone]: $0.320 \mathrm{moll}^{-1}$.

polymer is not dependent on styrene concentration within the 0.835 to $1.88 \mathrm{moll}^{-1}$ range, but is dependent at greater concentrations. Moreover, the rate constant $k_{\mathrm{d}}$ for mechanical degradation is $2.1 \times 10^{-7} \mathrm{~s}^{-1}$ in the range from 0.835 to 1.88 moll $1^{-1}$, and $4.2 \times 10^{-7} \mathrm{~s}^{-1}$ at $2.24 \mathrm{moll}^{-1}$. This is because the flexibility of the poly(vinyl chloride) chain is further decreased by the addition of greater quantities of styrene which is a poor solvent. Consequently, a violent chain scission occurred.

Figure 4 shows the effect of the concentrations of cyclohexanone and tetrahydrofuran on ultrasonic degradation. The rate of decrease in the numberaverage chain length was not found to depend on 


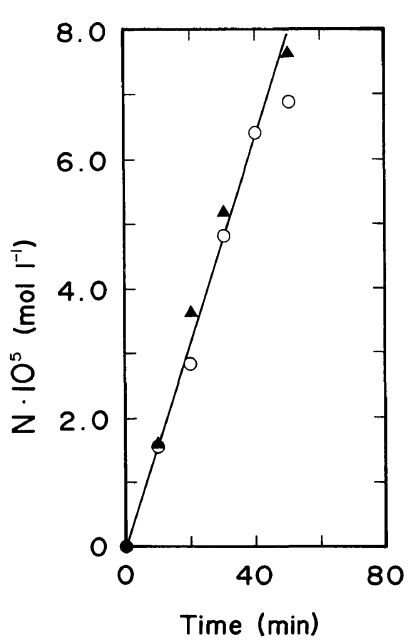

Figure 5. Number of chain scissions $v s$. irradiation time. [Cyclohexanone]/[Tetrahydrofuran]: $(\boldsymbol{\Delta}), 2.97$; (O), 0.368. [Poly(vinyl chloride)]: $0.0620 \mathrm{moll}^{-1}$. [Styrene]: $2.24 \mathrm{moll}^{-1}$. [ $p$-Benzoquinone]: $0.320 \mathrm{moll}^{-1}$.

the solvent concentration.

Figure 5 shows the change in the number of chain scissions $\left(\mathrm{moll}^{-1}\right)$ as calculated from Figure 4. The number of poly(vinyl chloride) scissions increases linearly with increasing irradiation time. The rate constant $k_{\mathrm{d}}$ for mechanical degradation was $4.2 \times 10^{-7} \mathrm{~s}^{-1}$.

The results indicate that the effect of styrene on degradation was greatest when there was a large increase in its concentration.

\section{Mechanochemical Copolymerization}

The end radicals of poly(vinyl chloride) result from ultrasonic degradation as follows:<smiles>CCC(Cl)CC(Cl)C(C)Cl</smiles>

$$
\left(\mathrm{P}_{\mathrm{A}}^{*}\right) \quad\left(\mathrm{P}_{\mathrm{B}}^{*}\right)
$$

Figures 6 and 7 show that the copolymerization of styrene depends on the polymeric free radicals produced by mechanical degradation. This copolymerization was inhibited completely by $p$-benzoquinone. When the solution, in the absence of poly(vinyl chloride) and $p$-benzoquinone, was sub-

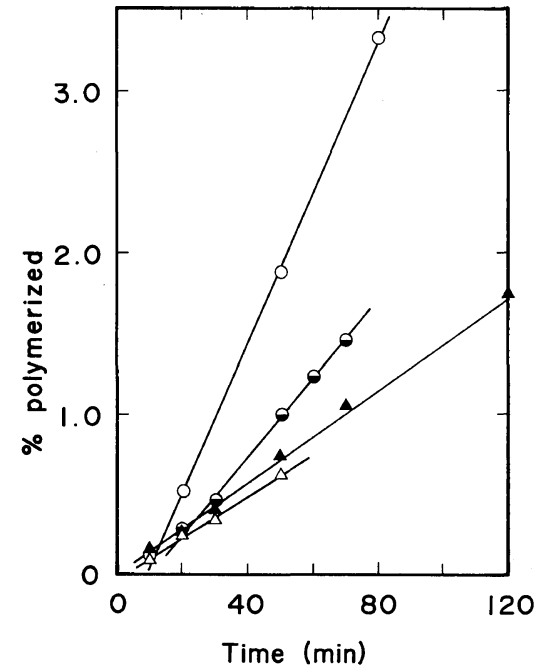

Figure 6. Effect of poly(vinyl chloride) concentrations on mechanochemical copolymerization. [Poly(vinyl chloride)]: (○), $0.141 \mathrm{moll}^{-1} ;(\ominus), 0.0950 \mathrm{moll}^{-1} ;(\mathbf{\Delta})$, $0.0570 \mathrm{moll}^{-1} ;(\triangle), 0.0520 \mathrm{moll}^{-1}$. [Styrene]: 2.39 moll ${ }^{-1}$. [Tetrahydrofuran]: $8.63 \mathrm{moll}^{-1}$. [Cyclohexanone]: $0 \mathrm{moll}^{-1}$.

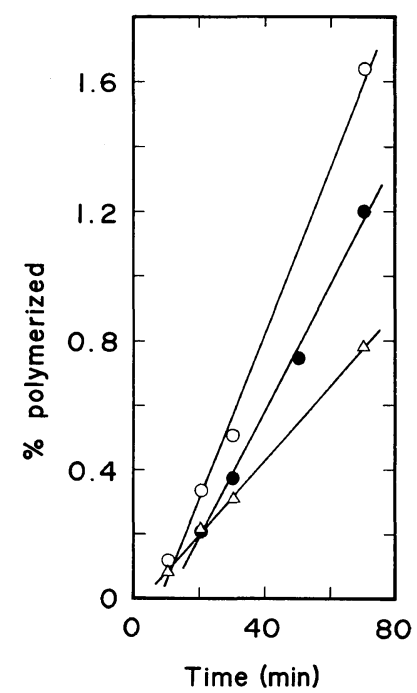

Figure 7. Effect of styrene concentrations on mechanochemical copolymerization. [Styrene]: $(\mathrm{O}), 1.92$ moll ${ }^{-1} ;(\bigcirc), \quad 1.43 \mathrm{moll}^{-1} ;(\triangle), 0.845 \mathrm{moll}^{-1}$. [Poly(vinyl chloride)]: $0.0660 \mathrm{moll}^{-1}$. [Cyclohexanone $] /[$ Tetrahydrofuran $]=0.736$.

jected to ultrasonic irradiation, the polymerization of styrene did not occur.

In Figure 6, the rate of polymerization increases 
with an increase in the concentration of poly(vinyl chloride) since large quantities of polymeric free radicals are produced (see Figure 2). This experiment was carried out in a system of poly(vinyl chloride)-styrene-tetrahydrofuran.

Figure 7 shows the effect of styrene concentrations on mechanochemical copolymerization, in a system of poly(vinyl chloride)-styrene-tetrahydrofuran-cyclohexanone. The rate of polymerization clearly increases with increasing styrene concentration.

Since the active ends of poly(vinyl chloride) fragments are responsible for the initiation of polymerization, the rate of mechanochemical copolymerization is derived from the following sequence of elementary reactions:

$\mathrm{P}_{0} \stackrel{k_{\mathrm{d}}}{\longrightarrow} \mathrm{P}_{\mathrm{A}}^{*}+\mathrm{P}_{\mathrm{B}}{ }^{*} \quad$ mechanical degradation $\left.\begin{array}{l}\mathrm{P}_{\mathrm{A}}^{*}+\mathrm{M} \stackrel{k_{\mathrm{iA}}}{\longrightarrow} \mathrm{P}_{\mathrm{A}}-\mathrm{M}^{*} \\ \mathrm{P}_{\mathrm{B}}^{*}+\mathrm{M} \stackrel{k_{\mathrm{iB}}}{\longrightarrow} \mathrm{P}_{\mathrm{B}}-\mathrm{M}^{*}\end{array}\right\}$ initiation

$\left.\begin{array}{l}\mathrm{P}_{\mathrm{A}}-\mathrm{M}^{*}+\mathrm{M} \underset{\mathrm{P}}{\stackrel{k_{\mathrm{P}}}{\longrightarrow}} \mathrm{P}^{*} \\ \mathrm{P}_{\mathrm{B}}-\mathrm{M}^{*}+\mathrm{M} \stackrel{k_{\mathrm{P}}}{\longrightarrow} \mathrm{P}^{*}\end{array}\right\}$ propagation

$\mathrm{P}^{*}+\mathrm{M} \stackrel{k_{\mathrm{tr}, \mathrm{M}}}{\longrightarrow} \mathrm{P}+\mathrm{M}^{*} \quad$ chain transfer to monomer (M)

$\mathrm{P}^{*}+\mathrm{P}_{\mathrm{x}} \stackrel{k_{\mathrm{tr}, \mathrm{P}}}{\longrightarrow} \mathrm{P}+\mathrm{P}_{\mathrm{x}}{ }^{*} \quad$ chain transfer to polymer $\left(\mathbf{P}_{\mathbf{x}}\right)$

$\mathrm{P}^{*}+\mathrm{S}_{1} \stackrel{k_{\mathrm{tr}, \mathrm{S}_{1}}}{\longrightarrow} \mathrm{P}+\mathrm{S}_{1}{ }^{*} \quad$ chain transfer to tetrahydrofuran $\left(\mathrm{S}_{1}\right)$

$\mathrm{P}^{*}+\mathrm{S}_{2} \stackrel{k_{\mathrm{tr}, \mathrm{S}_{2}}}{\longrightarrow} \mathrm{P}+\mathrm{S}_{2}{ }^{*} \quad$ chain transfer to cyclohexanone $\left(\mathrm{S}_{2}\right)$

$\mathrm{P}_{\mathrm{a}}^{*}+\mathrm{P}_{\mathrm{b}}^{*} \stackrel{k_{\mathrm{t}}}{\longrightarrow} \mathrm{P}_{\mathrm{a}+\mathrm{b}}, \mathrm{P}_{\mathrm{a}}+\mathrm{P}_{\mathrm{b}}$ termination

where $k_{\mathrm{d}}, k_{\mathrm{iA}}, k_{\mathrm{iB}}, k_{\mathrm{P}}, k_{\mathrm{tr}, \mathrm{M}}, k_{\mathrm{tr}, \mathrm{P}}, k_{\mathrm{tr}, \mathrm{S}_{1}}, k_{\mathrm{tr}, \mathrm{S}_{2}}$, and $k_{\mathrm{t}}$ are the respective reactions rate constants. When chain transfer reactions to tetrahydrofuran and cyclohexanone are much faster than the termination reaction, the initial rate of mechanochemical copolymerization $R_{\mathrm{p}}$ is given by:

$$
\frac{1}{R_{\mathrm{p}}\left[\mathrm{S}_{1}\right]}=\frac{1}{k_{\mathrm{d}} f\left[\mathrm{P}_{0}\right][\mathrm{M}]}\left\{\frac{k_{\mathrm{tr}, \mathrm{s}_{1}}}{k_{\mathrm{p}}}+\frac{k_{\mathrm{tr}, \mathrm{s}_{2}}\left[\mathrm{~S}_{2}\right]}{k_{\mathrm{p}}\left[\mathrm{S}_{1}\right]}\right\}
$$

where $\left[\mathrm{P}_{0}\right]$ and $[\mathrm{M}]$ are the initial concentrations of poly(vinyl chloride) (strictly speaking, the molar concentration of poly(vinyl chloride) above the

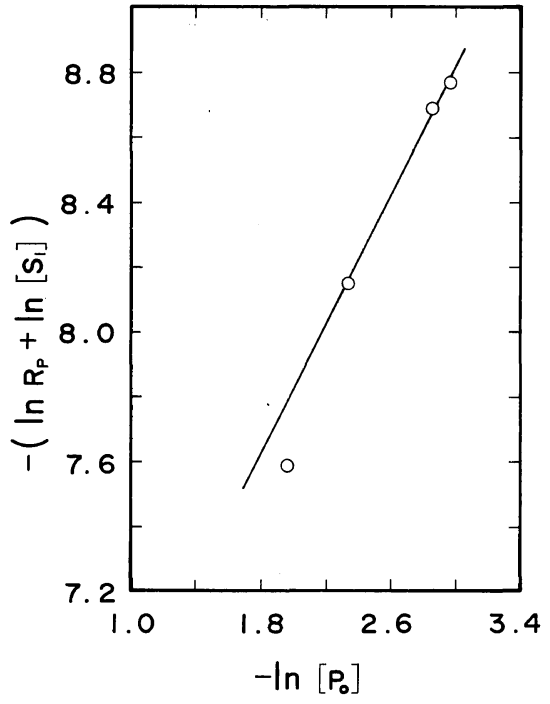

Figure 8. Relationship between $-\left(\ln R_{\mathrm{p}}+\ln \left[\mathrm{S}_{1}\right]\right)$ and $-\ln \left[\mathrm{P}_{0}\right]$ during mechanochemical copolymerization of styrene with poly(vinyl chloride). [Styrene]: $2.39 \mathrm{moll}^{-1}$. [Tetrahydrofuran]: $8.63 \mathrm{moll}^{-1}$. [Cyclohexanone]: 0 $\mathrm{moll}^{-1}$. $\left(R_{\mathrm{p}}: \mathrm{moll}^{-1} \mathrm{~s}^{-1}\right)$.

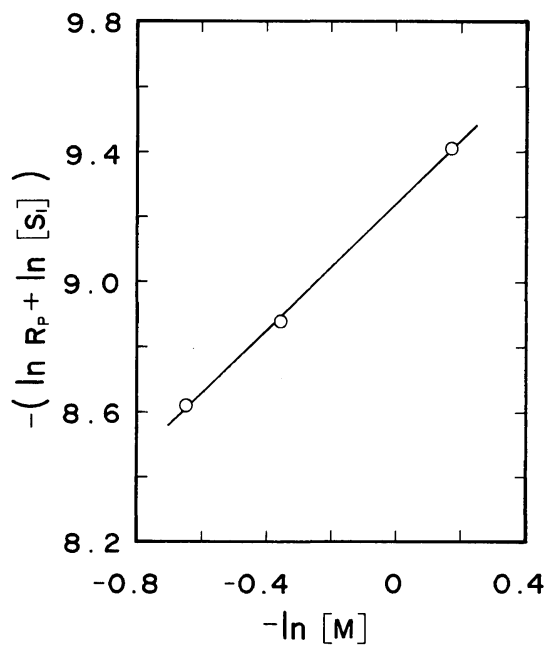

Figure 9. Relationship between $-\left(\ln R_{\mathrm{p}}+\ln \left[\mathrm{S}_{1}\right]\right)$ and $-\ln [\mathrm{M}]$ during mechanochemical copolymerization of styrene with poly(vinyl chloride). [Poly(vinyl chloride)]: $0.0660 \mathrm{moll}^{-1}$. [Cyclohexanone]/[Tetrahydrofuran] $=$ 0.736. $\left(R_{\mathrm{p}}: \mathrm{moll}^{-1} \mathrm{~s}^{-1}\right)$.

limiting chain length $\mathrm{P}_{1}$ ) and styrene. $\left[\mathrm{S}_{1}\right]$ and $\left[\mathrm{S}_{2}\right]$ are the concentrations of tetrahydrofuran and cyclohexanone. $F$ is the initiation efficiency of the active ends of the poly(vinyl chloride) fragments. 


\section{H. FuJiwara et al.}

The results from eq 2 are shown in Figures 8 and 9, where the relationships between $-\left(\ln R_{\mathrm{p}}+\ln \left[\mathrm{S}_{1}\right]\right)$ and $-\ln \left[\mathrm{P}_{0}\right]$ in Figure 8 and between $-\left(\ln R_{\mathrm{p}}+\ln \left[\mathrm{S}_{1}\right]\right)$ and $-\ln [\mathrm{M}]$ in Figure 9 are respectively illustrated. As is obvious from these figures, linear functions are found to conform to mechanochemical copolymerization. In addition, each value of the slopes of the straight line in these figures is 1.0. Accordingly, the initial rate of copolymerization $R_{\mathrm{p}}$ is given by $1 / R_{\mathrm{p}}\left[\mathrm{S}_{1}\right] \propto 1 /\left[\mathrm{P}_{0}\right][\mathrm{M}]$.

Changes in the Composition of the Copolymer and Homopolymer in the Reaction Products

The turbidimetric titration curves at various

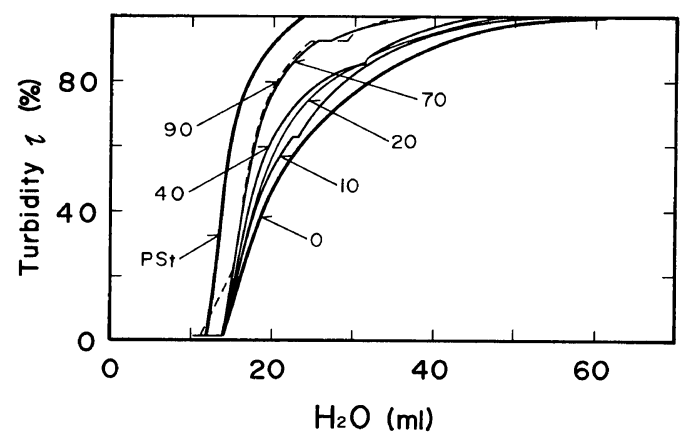

Figure 10. Turbidimetric titration curves at various stages during mechanochemical copolymerization. Samples ([Poly(vinyl chloride)]: $0.0710 \mathrm{moll}^{-1}$. [Styrene]: $2.36 \mathrm{moll}^{-1}$. [Cyclohexanone]/[Tetrahydrofuran] $=2.98)$ : (0), untreated poly(vinyl chloride) sample; (10), 10-min treatment; (20), 20-min treatment; (40), 40min treatment; (70), 70-min treatment; (90), 90-min treatment. (PSt), polystyrene produced by emulsion polymerization at $60^{\circ} \mathrm{C}\left(\bar{P}_{n}=2880\right)$. stages of copolymerization are shown in Figure 10. The titration curve of the original poly(vinyl chloride) has a smooth $S$ shape, but those of the samples after copolymerization are inflected. In particular, the titration curve of a sample after 90 minutes has two inflection points, one at the beginning and another at a later time. This suggests that the sample consists of trinary systems of polystyrene, the block copolymer of styrene with poly(vinyl chloride), and poly(vinyl chloride).

Figure 11 shows the changes in the composition of the block copolymer and homopolymers in the reaction products with respect to irradiation time. The compositions of two homopolymers and the block copolymer were calculated respectively from differential turbidimetric titration curves derived

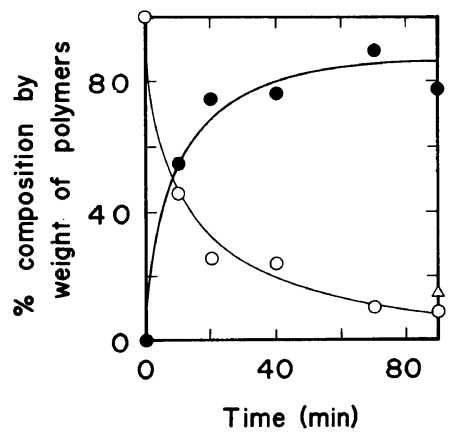

Figure 11. Changes in the composition of the block copolymer and homopolymers in the reaction products. Samples ([Poly(vinyl chloride)]: $0.0710 \mathrm{moll}^{-1}$. [Styrene]: $2.36 \mathrm{moll}^{-1}$. [Cyclohexanone]/[Tetrahydrofuran] = 2.98): $(\bigcirc)$, poly(vinyl chloride); $(\bigcirc)$, block copolymer; $(\triangle)$, polystyrene.

Table II. Apparent block ratio $A_{\mathrm{b}}{ }^{\mathrm{a}}$

\begin{tabular}{|c|c|c|c|c|c|}
\hline Time $/ \min$ & 10 & 20 & 40 & 70 & 90 \\
\hline Total amount of polymer, $B \times 10^{2} / \mathrm{g}$ & 5.57 & 6.51 & 7.25 & 10.90 & 11.89 \\
\hline $\begin{array}{l}\text { Poly(vinyl chloride) in the total } \\
\text { amount of polymer, } C \times 10^{2} / \mathrm{g}\end{array}$ & 4.76 & 4.77 & 4.78 & 4.82 & 4.77 \\
\hline Styrene polymerized, $D \times 10^{2} / \mathrm{g}$ & 0.81 & 1.74 & 2.47 & 6.08 & 7.12 \\
\hline Polystyrene, $E \times 10^{2} / \mathrm{g}$ & 0 & 0 & 0 & 0 & 1.87 \\
\hline Poly(vinyl chloride), $F \times 10^{2} / \mathrm{g}$ & 2.50 & 1.63 & 1.74 & 1.09 & 0.95 \\
\hline Block copolymer, $G \times 10^{2} / \mathrm{g}$ & 3.07 & 4.88 & 5.51 & 9.81 & 9.07 \\
\hline \multicolumn{6}{|l|}{ Poly(vinyl chloride) units in the } \\
\hline block copolymer, $H \times 10^{2} / \mathrm{g}$ & 2.26 & 3.14 & 3.04 & 3.73 & 3.82 \\
\hline Apparent block ratio, $A_{\mathrm{b}}^{\mathrm{a}} / \%$ & 47.5 & 65.8 & 63.6 & 77.4 & 80.1 \\
\hline
\end{tabular}

a Apparent block ratio, $A_{\mathrm{b}}(\%)=(H / C) \times 100$.

Samples ([Poly(vinyl chloride)], $0.0710 \mathrm{~mol} \mathrm{1}^{-1}$; [Styrene], $2.36 \mathrm{~mol} \mathrm{1}^{-1}$; [Cyclohexanone]/[Tetrahydrofuran] $=$ 2.98), polymeric samples. 
from Figure 10. ${ }^{21,23}$ The weight proportion of poly(vinyl chloride) decreases rapidly with the progress of the polymerization, but that of the block copolymer rapidly increases. In addition, the formation of polystyrene after 90 minutes is thought to occur since the polystyrene chain in the block copolymer undergoes mechanical scission during irradiation.

If we express the apparent block ratio $A_{\mathrm{b}}$ as the ratio of poly(vinyl chloride) units in the block copolymer to the total poly(vinyl chloride) content, it becomes:
Table II shows the change in the apparent block ratio $A_{\mathrm{b}}$ with respect to irradiation time. The value of $A_{\mathrm{b}}$ increases greatly with increasing time, and after 90 minutes reaches $80.1 \%$. This suggests that the active ends of poly(vinyl chloride) fragments produced by ultrasonic irradiation improve the efficiency of the mechanochemical polymerization of styrene. This follows naturally in consideration of the value of the reactivity ratio $r_{1}, r_{1}=0.02,{ }^{25}$ in the radical copolymerization of vinyl chloride $M_{1}$ and styrene $\mathrm{M}_{2}$ at $60^{\circ} \mathrm{C}$.

$$
A_{\mathrm{b}}(\%)=\frac{\text { Poly }(\text { vinyl chloride }) \text { units in the block copolymer }(\mathrm{g})}{\text { Poly }(\text { vinyl chloride }) \text { in the total amount of polymers }(\mathrm{g})} \times 100
$$

\section{REFERENCES}

1. G. Schmid and O. Rommel, Z. Phys. Chem., A, 185, 97 (1939); Z. Elektrochem., 45, 659 (1939).

2. G. Schmid and E. Beuttenmüller, Z. Elektrochem., 50, 209 (1944).

3. H. H. G. Jellinek and G. White, J. Polym. Sci., 6, 757 (1951).

4. N. Sato, H. Okuyama, and K. Chujo, Kolloid Z., 121, 46 (1951).

5. H. W. W. Brett and H. H. G. Jellinek, J. Polym. Sci., 13, 441 (1954).

6. V. A. Henglein, Makromol. Chem., 15, 188 (1955).

7. H. H. G. Jellinek, J. Polym. Sci., 22, 149 (1956).

8. M. A. K. Mostafa, J. Polym. Sci., 28, 519 (1958); 33, 311 (1958).

9. G. Gooberman and J. Lamb, J. Polym. Sci., 42, 35 (1960).

10. B. S. Eltsefon and A. A. Berlin, Vysokomol. Soedin., 4, 1033 (1962); ibid., 5, 1562 (1963).

11. S. Chandra, P. Roy-Chowdhury, and A. B. Biswas, J. Appl. Polym. Sci., 10, 1089 (1966).

12. A. M. Basedow and K. H. Ebert, Makromol. Chem., 176, 745 (1975).
13. H. Fujiwara, M. Tsunoda, and K. Goto, Kobunshi Ronbunshu, 32, 106 (1975).

14. C. B. Wu, P. J. Sheth, and J. F. Johnson, Polymer, 18, 822 (1977).

15. S. Kawase, H. Doi, and T. Kakurai, Kobunshi Ronbunshu, 35, 109 (1978).

16. J. Niezette and A. Linkens, Polymer, 19, 939 (1978).

17. V. A. Henglein, Makromol. Chem., 14, 128 (1954).

18. A. A. Berlin and A. M. Dubinskaya, Vysokomol. Soedin., 2, 1426 (1960).

19. H. Fujiwara, K. Okazaki, and K. Goto, J. Polym. Sci., Polym. Phys. Ed., 13, 953 (1975).

20. K. F. O'Driscoll and A. U. Sridharan, J. Appl. Polym. Sci., Appl. Polym. Symp., No. 26, 135 (1975).

21. H. Fujiwara, H. Kakiuchi, K. Kanmaki, and K. Goto, Kobunshi Ronbunshu, 33, 183 (1976).

22. S. Kawase, and T. Kakurai, Kobunshi Ronbunshu, 35, 185 (1978).

23. H. Fujiwara, K. Sasaki, K. Hochi, and K. Goto, Nippon Gomu Kyokaishi, 52, 247 (1979).

24. K. Goto and H. Fujiwara, Kobunshi Kagaku, 23, 827 (1966).

25. K. W. Doak, J. Amer. Chem. Soc., 70, 1525 (1948). 